\title{
Escala de identificação de dotação e talento: Construção de instrumento e validade de conteúdo
}

Márcia de Fátima Rabello Lovisi de Freitas

Patricia Waltz Schelini

\section{RESUMO}

O uso de escalas para avaliação de talentos por professores pode evitar subidentificação. Esse estudo consistiu na elaboração de uma escala para identificação de talentos e análise de evidências de validade de conteúdo por meio de avaliação de juízes. Participaram cinco especialistas. Utilizou-se a Escala de Identificação de Dotação e Talento, com 120 itens e seis domínios (capacidades intelectuais, criatividade, competência social, inteligência prática, capacidades artísticas/musicalidade e capacidades psicomotoras). Os itens foram aleatoriamente distribuídos e enviados aos juízes. 0 índice de concordância geral entrejuízes foi de $82 \%$. Dos 120 itens iniciais, 22 deveriam ser excluídos e 42 modificados na escrita. A versão final constituiu-se por 98 itens. Ressalta-se que outros estudos devem analisar a estrutura fatorial da escala para complementar a análise de suas propriedades psicométricas.

Palavras-chave: dotação; talento; identificação; validade; psicometria.

\section{ABSTRACT \\ Scale of giftedness and talent identification: instrument construction and content validity}

The use of scales talent assessment by teachers can avoid sub identification. In the present study, we designed a scale for identifying talent and analyzed evidence of its content validity by means of judges evaluation. Five experts took part of the study. We used the Scale of Giftedness and Talent Identification, with 120 items and six domains (intellectual abilities, creativity, social competence, practical intelligence, artistic skills/musicality and psychomotor skills). The items were randomly distributed and sent to the judges. The general inter-judge agreement rate was $82 \%$. Of the 120 initial items, 22 should be deleted and 42 , rewritten. The final version consisted of 98 items. Further studies should examine the factor structure of the scale to complement the analyses of its psychometric properties.

Keywords: giftedness, talent, identification, validity, psychometrics.

Diversos termos têm sido utilizados no Brasil como sinônimos de capacidade elevada em alguma área do conhecimento. Entre eles, pode-se destacar dotação, talento, altas habilidades, superdotação, potencial elevado, genialidade, entre outros. Kaufman e Sternberg (2008), entretanto, destacam que tais termos são apenas rótulos, independente do nome que seja atribuído. Segundo os autores, existem diferentes critérios para definir quais crianças se associam ou não a esses rótulos e não há critério absoluto ou correto. Por isso, há muitas divergências sobre a forma como devem ser aplicados, o que aponta para a falta de consenso teórico na área. Assim, as conceituações remontam a perspectivas teóricas que nem sempre são compatíveis entre si. Buscando delimitar a fundamentação teórica e epistemológica que embasa este trabalho, as palavras dotação (giftedness) e talento (talent) serão usadas conjuntamente ao longo do texto, diferentemente da terminologia oficial da legislação brasileira, que faz uso das palavras altas habilidades/superdotação.

Segundo Gagné (2013), existe uma distinção bem clara entre esses dois conceitos. Para

\section{Sobre os Autores}

M.F.R.L.F.

orcid.org/0000-0001-6478-3559

Universidade Federal de São

Carlos - São Carlos, SP

marciafreitaspsi@gmail.com

P.W.S.

orcid.org/0000-0002-2765-865X

Universidade Federal de São

Carlos - São Carlos, SP

pws@ufscar.br

\section{Direitos Autorais}

Este é um artigo de acesso aberto e pode ser reproduzido livremente, distribuído,

transmitido ou modificado, por qualquer pessoa desde que usado sem fins comerciais. 0 trabalho é disponibilizado sob a licença Creative Commons CCBY-NC. 


\section{H. INTERACÃO EM 1. PSICOLOGIA}

ele, a dotação diz respeito à posse e ao uso de capacidades naturais elevadas, que existem no indivíduo de forma espontânea, sem treinamento. Já o talento implica no desempenho notável de habilidades ou conhecimentos que foram sistematicamente desenvolvidos. Portanto, um indivíduo talentoso se caracteriza por ter suas capacidades elevadas naturais amplamente desenvolvidas. Entende-se com isso que os termos altas habilidades/superdotação e dotação e talento, apesar de serem utilizados como sinônimos, refletem bases teóricas distintas. Dotação e talento são termos que apontam mais claramente para um princípio desenvolvimentista e processual das capacidades elevadas (Horowitz, 2009). Assim, o conceito composto dotação e talento (D\&T) legitima o embasamento teórico deste trabalho.

Apesar de alunos com D\&T terem respaldo da legislação e das políticas brasileiras para 0 atendimento de suas necessidades educacionais, elas só podem ser atendidas depois que forem identificadas. No Brasil, há poucos programas que investem no reconhecimento e no desenvolvimento de alunos com D\&T durante as etapas escolares. Porém, não se pode ignorar o avanço da área nas últimas décadas, inclusive com maior visibilidade a esse aluno e uma maior preocupação em atender suas necessidades no contexto escolar. 0 processo de reconhecimento das características de D\&T é chamado de identificação e pode acontecer de diferentes formas e por variados caminhos, visto que identificar alunos com D\&T demanda uma busca ativa e longitudinal por essas características e, para isso, é necessário o uso de diversas fontes de informação, como professores, pais, pares e/ou o próprio aluno (Renzulli \& Gaesser, 2015).

Uma das etapas da identificação de alunos com D\&T, que é realizada por meio da avaliação dos docentes, é conhecida como nomeação por professores. A nomeação por professores pode ser considerada uma alternativa complementar e necessária às medidas padronizadas, devendo ser usada em conjunto com outras fontes de identificação, e não isoladamente, como já ressaltado. Alguns estudos (Gagné, 1994; Hodge \& Kemp, 2006) apontam que professores são boas fontes de informação para a indicação de alunos com D\&T, uma vez que ocupam posição privilegiada no processo de ensino-aprendizagem. Etapas complementares da identificação de D\&T incluem a aplicação de testes de inteligência, criatividade e outras características cognitivas e de personalidade, instrumentos e escalas sobre motivação, clima escolar, clima familiar e outras variáveis ambientais importantes para o contexto do aluno e a busca de informações desenvolvimentais com a família, os pares e o próprio aluno.
Márcia de Fátima Rabello Lovisi de Freitas e Patrícia Waltz Schelini

A nomeação por professores pode ser feita por meio de instrumentos validados para esse fim de acordo com o contexto onde serão aplicados. Barbosa, Schelini e Almeida (2012) notam que há carência de medidas válidas e fidedignas para serem utilizadas na identificação de alunos com D\&T. As principais lacunas apresentadas pelos autores são de medidas que avaliem outros domínios menos explorados por testes padronizados, como o psicomotor e o emocional, bem como de instrumentos desenvolvidos especificamente para identificar D\&T. Vale lembrar, novamente, que os testes são relevantes e devem ser incluídos, mas não são suficientes à identificação, uma vez que outros procedimentos como observação e entrevistas precisam ser considerados.

Considerando a necessidade de inclusão de outros domínios de D\&T menos explorados por medidas padronizadas e de variáveis importantes que influenciam no processo de identificação, o Modelo de Dotação de Munique (MDM) (Heller, 2004; Heller, 2005; Heller, 2012; Heller \& Perleth, 2008; Heller, Perleth, \& Lim, 2005) vem se mostrando como uma alternativa teórica coerente, na medida em que compreende o talento como produto de um processo sistemático de aprendizagem, influenciado por fatores ambientais e genéticos (Heller \& Perleth, 2008), compartilhando da definição apresentada por Gagné (2013). De acordo com Heller et al. (2005), o MDM objetiva integrar, em um modelo de D\&T único e coeso, o papel das características individuais e ambientais na identificação e no desenvolvimento do talento (Figura 1). Nesse sentido, se diferencia de outras propostas teóricas, como a de Renzulli (2011), por também incluir as características individuais e ambientais, denominadas moderadores, como fatores ativos do processo de identificação de D\&T. O MDM ainda parece ser pouco conhecido no Brasil, pois encontrou-se apenas o trabalho de Nakano e Siqueira (2012) embasado neste modelo.

Para a identificação de D\&T, a diferenciação entre preditores, moderadores e variáveis de critérios se faz importante (Heller, 2004; Heller et al., 2005), pois permite compreender de que modo as capacidades individuais podem se tornar habilidades sistematicamente desenvolvidas, destacando-se a influência dos moderadores nesse processo. Os preditores são capacidades relativamente independentes uma das outras e são considerados indicadores do talento (Heller, 2004). Pode-se deduzir que os preditores representam as dotações ou capacidades naturais do indivíduo, apesar desse nome não ser utilizado na definição do modelo. Essas capacidades se tornam desempenho observável por meio da atuação de moderadores, que podem ser intrínsecos ou ambientais e que facilitam ou dificultam o processo de desenvolvimento do 


\section{站 NTERACÃOEM PSICOLOGIA}

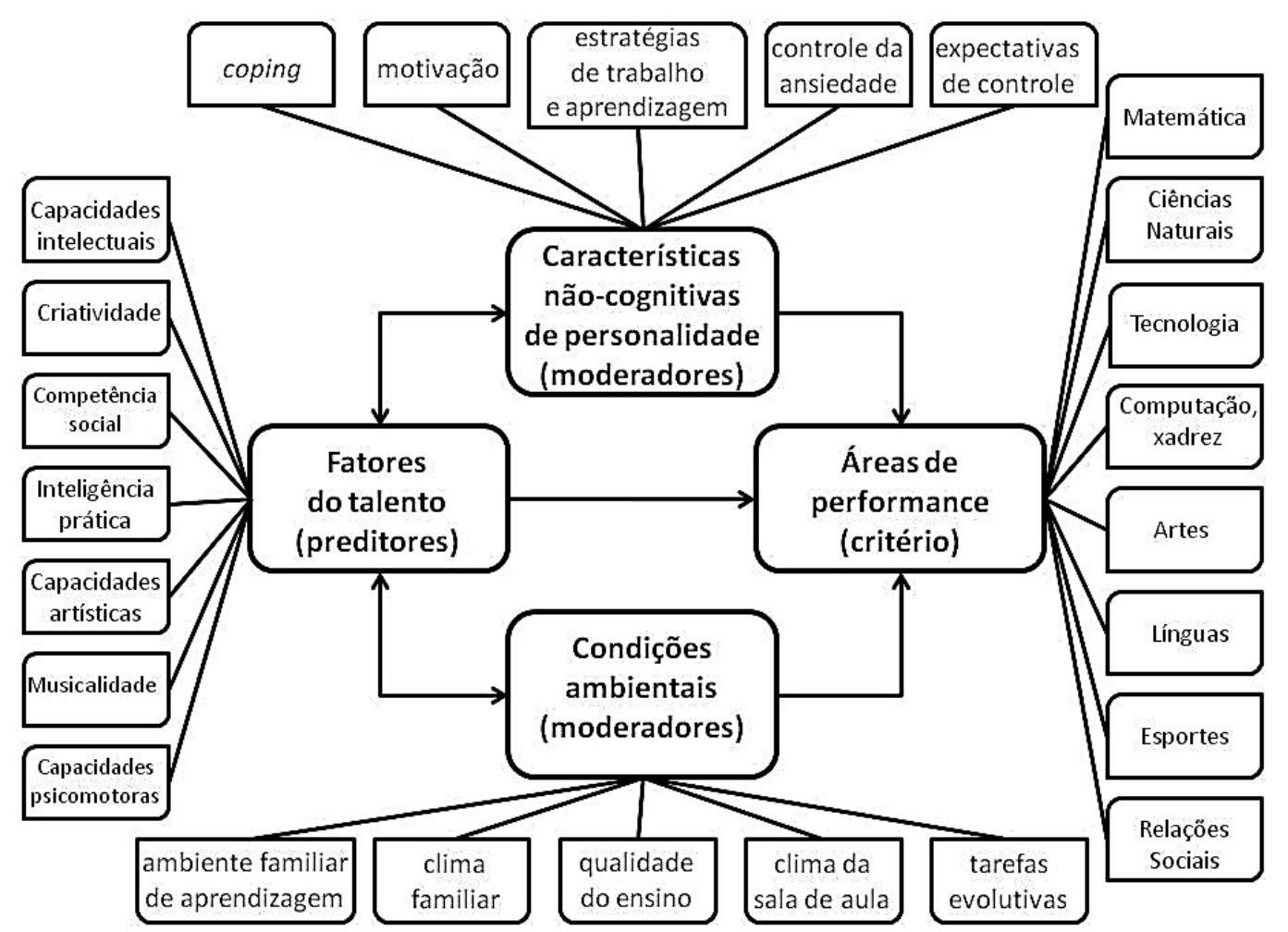

Figura 1. Modelo de Dotação de Munique.

Nota. De "Identification of gifted and talented students", de K. A. Heller, 2004. Psychology Science, 46, p. 304. Direitos autorais de 2004 por Psychology Science. Adaptada com permissão do autor.

talento. As variáveis de critério são relacionadas ao desempenho do indivíduo em áreas mais ou menos específicas, de acordo com o tipo de talento (Heller, 2004). Assim, de acordo com o MDM, o talento é desenvolvido em um indivíduo a partir de preditores já existentes, com o auxílio das variáveis que mediam tal processo. O MDM estabelece ainda sete domínios básicos de D\&T que se sobrepõem aos preditores, como pode ser observado na Figura 1. De acordo com Heller (2004) são: 1) capacidades intelectuais, 2) criatividade, 3) competência social, 4) inteligência prática, 5) capacidades artísticas, 6) musicalidade e 7) capacidades psicomotoras.

De acordo com Heller e Perleth (2008), um processo de identificação de D\&T adequado necessita ser multidimensional, incluindo o maior número possível de variáveis. 0 processo ideal se inicia com uma triagem da população escolar, que deve incluir $100 \%$ dos alunos do primeiro ciclo do Ensino Fundamental. Durante essa primeira etapa, professores, pais e os próprios alunos preenchem checklists e especialistas realizam observações comportamentais dos alunos no ambiente escolar. Cerca de
$10 \%$ a $20 \%$ dos alunos são rastreados como potencialmente talentosos durante a triagem. Em uma segunda etapa da identificação, os alunos potencialmente talentosos são submetidos à aplicação de medidas padronizadas de inteligência, escalas e questionários. São avaliadas variáveis preditoras e moderadoras. Esse momento da avaliação busca estabelecer critérios de objetividade, fidedignidade e validade das medidas, de modo a minimizar efeitos de teto das medidas padronizadas, privilegiando a discriminação da amostra. Finalizada a segunda etapa, cerca de $2 \%$ a $5 \%$ do grupo de alunos será identificado com características de D\&T. Avaliações individuais e mais detalhadas poderão ser feitas para encaminhar os alunos identificados para programas de desenvolvimento de talentos (Heller, 2004; Heller \& Perleth, 2008).

Visto que há carência de medidas válidas e precisas voltadas especificamente à identificação de D\&T no Brasil e considerando o MDM como uma proposta teórica útil para suprir as carências da área, como apresentado por Barbosa, Schelini e Almeida (2012), o presente trabalho objetivou elaborar uma escala para identificação de características de 


\section{-4: INTERACÃO EM LF PSICOLOGIA}

D\&T, baseada no processo de identificação proposto pelo MDM. Optou-se pela construção de um novo instrumento pelo fato da escala ser dedicada a professores, sofrendo influência do nosso sistema educacional e da maneira como as disciplinas estão organizadas, o que pode propiciar especificidades no que se refere à possibilidade de observação dos alunos. Especificamente, o objetivo deste trabalho foi elaborar itens para a construção de um instrumento que objetiva rastrear características de D\&T em alunos de $4^{\circ}, 5^{\circ}$ e $6^{\circ}$ anos do Ensino Fundamental por meio da nomeação de professores e analisar as evidências de validade baseadas no conteúdo da escala.

Estudos sobre validade de conteúdo devem verificar a representatividade dos itens de uma escala em relação aos fatores ou dimensões que o instrumento se propõe a medir (Primi, Muniz \& Nunes, 2009). Pasquali (1999) salienta que a análise da pertinência dos itens deve ser feita por juízes especialistas no tema, visto que necessitam avaliar se os itens se referem ou não às características ou comportamentos em questão. Ressalta-se novamente que a identificação de D\&T é um processo amplo, dinâmico e contínuo. Deve-se compreender que 0 instrumento desenvolvido busca rastrear características de D\&T e não diagnosticá-las, em conformidade com a primeira etapa de identificação descrita no MDM.

\section{MÉTODO}

\section{PARTICIPANTES}

A fim de avaliar as evidências de validade baseadas no conteúdo da escala, foram escolhidos cinco especialistas em D\&T (sendo três mestres e dois doutores) e com conhecimentos básicos sobre o Modelo de Dotação de Munique (Heller et al., 2005) para atuarem como juízes. Os juízes possuem dissertações e/ou teses na área de D\&T e conhecem o MDM, apesar de não terem trabalhado diretamente com este modelo em suas respectivas dissertações e teses.

\section{INSTRUMENTO}

Utilizou-se a Escala de Identificação de Dotação e Talento (EIDT), elaborada por Freitas (2016) para atingir os objetivos deste trabalho. A EIDT é uma escala do tipo Likert, de 4 pontos, que se propõe a rastrear características de D\&T em alunos de $4^{\circ}, 5^{\circ}$ e $6^{\circ}$ anos do Ensino Fundamental. A escala deve ser respondida pelo professor que, após ler o item, atribui um valor entre 1 e 4 para cada aluno avaliado, sendo que 1 equivale a "nunca", 2 a "quase nunca", 3 a "quase sempre" e 4 a "sempre", considerando a frequência do comportamento expresso pelo item.

A construção dos itens da escala se baseou nos sete preditores do MDM, que definiram os domínios a serem mensurados pela escala. Cabe destacar aqui que não foi encontrada uma operacionalização desses preditores na literatura sobre o modelo disponível em inglês. Inicialmente, a EIDT foi composta por 120 itens, divididos em seis domínios ou subescalas, são eles: capacidades intelectuais, criatividade, competência social, inteligência prática, capacidades artísticas/musicalidade e capacidades psicomotoras. Os domínios capacidades artísticas e musicalidade foram agrupados em um único fator, diferentemente do original, devido às especificidades do sistema educacional brasileiro, de modo a facilitar a construção dos itens e as respostas da escala.

Heller (2004) e Heller e Perleth (2008), em trabalhos nos quais descrevem uma bateria de testes de altas habilidades baseada no MDM e usada na Alemanha, apresentam alguns itens de checklists elaborados para rastreio de características de D\&T. A partir dos detalhamentos que apresentam dos domínios capacidades intelectuais, criatividade e competência social, por meio da apresentação de itens dos checklists, foi possível incluir características mais precisas dessas medidas na EIDT. As definições constitutivas desses e dos outros três domínios da escala também se basearam em modelos afins, de modo a agregar informações teóricas consistentes a cada domínio a ser medido pela escala.

Complementou-se o domínio capacidades intelectuais com a Teoria das Capacidades Cognitivas de Cattell-HornCarroll ou Teoria CHC (Campos \& Nakano, 2012; McGrew, 2009; Nisbett et al., 2012), o domínio criatividade com o modelo de criatividade de Torrance (Kim, 2011) e o domínio competência social com as teorias sobre inteligência emocional e habilidades sociais (França-Freitas, Del Prette \& Del Prette, 2014; Topping, Bremner \& Holmes, 2002). Já os domínios capacidades artísticas/musicalidade e capacidades psicomotoras foram compreendidos à luz da teoria das inteligências múltiplas de Gardner (Gardner, Chen \& Moran, 2010) e o domínio inteligência prática, de acordo com a teoria triárquica de Sternberg (Hedlund \& Sternberg, 2002; Sternberg, 2015). A operacionalização dos domínios baseadas nesses referenciais estão descritas em seguida.

Desse modo, foram propostos 120 itens que compuseram a primeira versão da EIDT. O domínio Capacidades Intelectuais envolve inteligência fluida (capacidade de estabelecer relações entre informações ou estímulos que é pouco influenciada pelo meio), inteligência cristalizada (conhecimento adquirido, tanto quantitativo, quanto de linguagem), memória de curto e longo prazo, rapidez de 


\section{INTERACÃO EM LF PSICOLOGIA}

raciocínio ou tempo de reação, áreas de interesse consolidadas (ser especialista em um tema, por exemplo), conhecimentos avançados e precocidade intelectual. 0 domínio foi composto por 28 itens.

O domínio Criatividade envolve originalidade (capacidade de produzir ideias raras e incomuns), pensamento divergente (formulação de alternativas a partir de uma informação dada), fluência (produção do maior número possível de ideias, ênfase na quantidade de respostas), flexibilidade (capacidade de produzir ideias diversificadas, de diferentes categorias ou sob vários pontos de vista) e curiosidade e interesses (busca ativa por conhecimento), incluiu 23 itens.

O domínio Competência Social pode ser definido como o uso eficaz das habilidades sociais. A ênfase está na capacidade de alcançar resultados sociais, pois possuir a capacidade não é sinônimo de que ela seja bem empregada. Envolve sensibilidade para problemas/empatia, cooperação, adaptabilidade social, cognições sociais e habilidades sociais. Esse englobou 20 itens.

O domínio Inteligência Prática caracteriza-se pelo uso de habilidades intelectuais para resolver problemas práticos. É um tipo de inteligência voltada a tarefas cotidianas e do senso comum e não a tarefas intelectuais ou acadêmicas. Envolve automotivação, auto-organização em tarefas do dia a dia, administração de relacionamentos pessoais, funcionamento de maneira eficaz em interações sociais, entendimento de informações sociais verbais e não-verbais, conhecimento sobre como realizar tarefas específicas, planejamento de atividades, monitoramento do progresso delas e avaliação de resultados. Constituiu-se por 15 itens.

O domínio Capacidades Artísticas/musicalidade engloba dois fatores que estão originalmente separados no MDM. Todavia, dada a estruturação dos currículos escolares no Brasil, optou-se por juntar ambos em uma única categoria ou fator. Entende-se por capacidades artísticas toda e qualquer capacidade que busca como resultado final uma produção ou expressão artística, seja ela desenho, pintura, dança, música, etc. Musicalidade é definida como a habilidade de perceber e utilizar melodias, timbres e ritmos, de criar, se comunicar e perceber significados através de sons. Esse domínio incluiu 16 itens.

Finalmente, o domínio Capacidades Psicomotoras diz respeito à facilidade de expressão por meio de movimentos corporais, como usar objetos ou utilizar todo o corpo ou partes dele na solução de problemas ou na construção de produtos e englobou 18 itens.
Márcia de Fátima Rabello Lovisi de Freitas e Patrícia Waltz Schelini

\section{PROCEDIMENTOS}

O desenvolvimento da pesquisa se iniciou somente após a aprovação do projeto pelo Comitê de Ética em Pesquisas com Seres Humanos da Universidade Federal de São Carlos. Após a elaboração, os itens da escala foram distribuídos aleatoriamente em um formulário on-line, que foi enviado individualmente para cada juiz por e-mail. Os juízes avaliaram o conteúdo dos itens, sua relevância e adequação ao público, além de destacarem mudanças possíveis na escrita dos itens.

O formulário enviado aos juízes continha o consentimento para participação na pesquisa, a definição constitutiva de cada um dos seis domínios, como apresentadas anteriormente e, logo abaixo das definições, o item em questão que deveria ser avaliado como pertencente a um dos domínios, sendo possível escolher apenas um entre os seis. A questão seguinte averiguava a adequação do item ao público proposto, por meio das alternativas "está adequado", "precisa ser alterado" ou "deve ser excluído", sendo possível marcar apenas uma resposta. Havia, ainda, um espaço para o juiz propor alterações ou sugestões na escrita do item, sendo que essa resposta não era obrigatória. Todos os participantes consentiram por escrito para compor a pesquisa e o Comitê de Ética foi favorável ao desenvolvimento do trabalho.

O processo de elaboração e aplicação da EIDT respeitou os procedimentos éticos necessários para pesquisas com seres humanos, sendo que o desenvolvimento do estudo se iniciou somente após a aprovação do projeto de pesquisa pelo Comitê de Ética em Pesquisas com Seres Humanos da Universidade Federal de São Carlos, bem como considerou as diretrizes nacionais (CFP, 2003) e internacionais (ITC, 2013) para elaboração e uso de testes psicológicos.

As evidências de validade com base no conteúdo da EIDT foram analisadas por meio da concordância das respostas dos cinco juízes especialistas. As respostas dos juízes foram alocadas em uma planilha de dados. De acordo com as recomendações de Pasquali (1999), determinou-se que o nível de concordância entre juízes para cada item deveria ser no mínimo $80 \%$ para que o item pudesse compor a nova versão da EIDT. Ainda segundo o autor, se a porcentagem de concordância entre juízes é baixa (menor que $80 \%$ ), isso significa que a dimensão do construto expressa pelo item não abrangia plenamente o conceito proposto e, por isso, os juízes classificam o item como pertencente a outros construtos. Nesse sentido, o autor recomenda a exclusão do item e a revisão ou reformulação dos itens e da definição constitutiva do domínio a ser mensurado antes que o instrumento seja aplicado na população alvo. 


\section{W"INTERACÃO EM ET PSICOLOGIA}

\section{RESULTADOS}

As análises da concordância entre juízes revelaram que o índice de concordância geral obtido para a EIDT foi de $82 \%$. Segundo Primi et al. (2009), quando a porcentagem de concordância é alta, significa que os juízes avaliaram os itens do instrumento como pertencentes às mesmas dimensões. Assim, os itens se tornam adequados para medir as características propostas e podem ser aplicados no público alvo da pesquisa.

Ainda, de acordo com a avaliação dos especialistas, dos 120 itens iniciais da EIDT, 22 deveriam ser excluídos por apresentarem concordância interjuízes inferior a $80 \%$, por obterem índices de concordância em outros domínios que não os originalmente propostos, por apresentarem sugestões de modificações na escrita que justificavam sua exclusão ou por não discriminarem suficientemente bem o comportamento expresso no item. Restaram, portanto, 98 itens que compuseram a nova versão da escala.

Dos 22 itens excluídos, 15 foram automaticamente retirados da nova versão da escala por apresentarem índice de concordância entre juízes menor que $80 \%$. Os itens e os índices obtidos na concordância dos juízes especialistas podem ser visualizados na Tabela 1.

Considerando os demais itens excluídos da escala, três deles, originalmente elaborados como pertencentes ao domínio capacidades intelectuais, foram excluídos por apresentarem o valor mínimo de concordância entre juízes em outros domínios que não o proposto inicialmente, o que justifica suas exclusões. 0 item 6 ("É muito questionador(a) e crítico(a), às vezes parecendo ser atrevido(a) ou provocador(a)") foi classificado pelos especialistas como pertencente ao domínio criatividade. 0 item 15 ("Consegue realizar rapidamente tarefas comuns, em um dado limite de tempo") foi classificado como inteligência prática e o item 25 ("Tem grande capacidade para se comunicar oralmente, possui fluência do pensamento e da fala"), como competência social. O item 38 ("A expressão artística [desenhos, pinturas, etc.] é bastante original"), inicialmente elaborado como um item do domínio criatividade, foi classificado de forma unânime pelos juízes como pertencente ao domínio capacidades artísticas/musicalidade, o que justifica a exclusão desse item da escala.

Os itens 117 ("Cria novos produtos fazendo uso do próprio corpo") e 118 ("Planeja invenções fazendo uso do próprio corpo"), apesar de terem alcançado o índice mínimo de concordância entre juízes como pertencentes ao domínio capacidades psicomotoras, receberam sugestões de alteração da escrita que justificam sua exclusão. Finalmente, o item 120 ("Sempre se envolve em atividades que requerem o uso do corpo"), que também obteve concordância unânime com o domínio capacidades psicomotoras, foi destacado por um dos juízes como um item sem discriminação suficiente do comportamento, visto que qualquer atividade requer uso do corpo. Dessa forma, optou-se pela exclusão do item. 0 domínio competência social obteve índice de concordância entre juízes de $100 \%$ para todos os itens, sendo a dimensão melhor avaliada na escala pelos especialistas.

Dos 98 itens que foram mantidos, 42 tiveram modificações na escrita propostas pelos juízes, a fim de facilitar o entendimento dos respondentes. Os juízes sugeriram mudanças na redação dos itens, como troca de palavras, troca na ordem de apresentação das palavras e inclusão ou exclusão de palavras. Cita-se, por exemplo, a mudança proposta no item 51, do fator criatividade, originalmente escrito "valoriza bastante a quantidade de ideias" e alterado para "tem grande quantidade de ideias". Outro item com alterações na escrita foi o item 60 , do fator competência social, originalmente escrito "expressa suas opiniões e sentimentos de modo firme e coerente, dizendo o que pensa, mas sem ferir ou magoar outras pessoas" e alterado para "expressa suas opiniões e sentimentos sem magoar outras pessoas". As sugestões dos especialistas foram acatadas em sua maioria e incorporadas aos itens por terem sido consideradas úteis e relevantes para o aprimoramento da escala. As sugestões não acatadas incluíam troca de voz passiva para ativa, por exemplo, sendo irrelevantes para aprimorar a compreensão do item.

\section{DISCUSSÃO}

O procedimento de enviar escalas ou instrumentos construídos para determinada finalidade para a avaliação de juízes especialistas é considerado como uma importante etapa da construção de instrumentos psicológicos. Neste estudo, foi possível perceber que os juízes foram capazes de apresentar sugestões e alternativas de reescrita que facilitaram a compreensão dos itens da escala pelos participantes.

Um questionamento pode ser feito em relação ao fato de não haver, na literatura, uma operacionalização dos domínios do MDM, de forma a dificultar as evidências de que os itens contidos na EIDT estão em consonância com o modelo teórico. Para responder a tal indagação, cabe mencionar que o MDM é uma proposta teórica ainda em construção e, sem dúvida, passível de críticas. A maior delas, talvez, seja justamente o fato de que seus autores não especificam de maneira exaustiva os domínios avaliados. Isso não é um aspecto negativo apenas do MDM, mas a presente pesquisa e estudos posteriores que já foram submetidos à publicação pelas autoras visam contribuir para o enriquecimento do modelo e das definições de seus domínios. Uma das 
Tabela 1. Itens excluidos da escala por não alcançarem o indice minimo de concordância interjuizes

\begin{tabular}{|c|c|c|}
\hline $\begin{array}{l}\mathrm{N}^{\circ} \text { do } \\
\text { item }\end{array}$ & Item & $\begin{array}{c}\text { Índice de } \\
\text { concordância } \\
(\%)\end{array}$ \\
\hline \multicolumn{3}{|c|}{ FATOR CAPACIDADE INTELECTUAL } \\
\hline 7 & $\begin{array}{l}\text { Reflete bastante sobre um problema, analisando toda a situação e } \\
\text { fazendo comparações com outras informações. }\end{array}$ & $60 \%$ \\
\hline 9 & $\begin{array}{l}\text { Tem interesses consolidados em algumas áreas, podendo ser } \\
\text { especialista em um tema. }\end{array}$ & $60 \%$ \\
\hline 11 & $\begin{array}{l}\text { Diante de uma situação nova ou de aprendizado, consegue facilmente } \\
\text { reorganizar, transformar e generalizar as informações. }\end{array}$ & $60 \%$ \\
\hline 24 & $\begin{array}{l}\text { Expressa facilmente o que pensa por meio da escrita (histórias, poemas } \\
\text { etc). }\end{array}$ & $60 \%$ \\
\hline \multicolumn{3}{|c|}{ FATOR CRIATIVIDADE } \\
\hline 30 & Consegue pensar em diferentes formas de resolver um único problema. & $60 \%$ \\
\hline 31 & É bastante curioso(a), quer entender como as coisas funcionam. & $60 \%$ \\
\hline 39 & $\begin{array}{l}\text { É capaz de identificar falhas ou lacunas em uma situação e criar } \\
\text { complementos para isso. }\end{array}$ & $60 \%$ \\
\hline 48 & $\begin{array}{l}\text { Costuma ser bastante curioso(a), podendo até se arriscar em muitas } \\
\text { situações. }\end{array}$ & $60 \%$ \\
\hline 50 & $\begin{array}{l}\text { Pensa rapidamente em muitas formas de se resolver um problema e não } \\
\text { se contenta com soluções comuns. }\end{array}$ & $60 \%$ \\
\hline \multicolumn{3}{|c|}{ FATOR INTELIGÊNCIA PRÁTICA } \\
\hline 77 & $\begin{array}{l}\text { Consegue reconhecer facilmente um problema quando está diante de } \\
\text { uma situação embaraçosa. }\end{array}$ & $60 \%$ \\
\hline 83 & É capaz de fazer coisas que nunca lhe foram ensinadas. & $60 \%$ \\
\hline 85 & $\begin{array}{l}\text { Sabe facilmente como fazer as coisas, mesmo que ninguém lhe tenha } \\
\text { ensinado. }\end{array}$ & $60 \%$ \\
\hline \multicolumn{3}{|c|}{ FATOR CAPACIDADES ARTÍSTICAS / MUSICALIDADE } \\
\hline 99 & $\begin{array}{l}\text { Em tarefas artísticas, inova e cria soluções originais para os desafios que } \\
\text { lhe propõem. }\end{array}$ & $60 \%$ \\
\hline \multicolumn{3}{|c|}{ FATOR CAPACIDADES PSICOMOTORAS } \\
\hline 112 & Imita facilmente o modo com as pessoas andam, falam e se mexem. & $60 \%$ \\
\hline 116 & É capaz de usar facilmente o próprio corpo para expressar suas emoções. & $60 \%$ \\
\hline
\end{tabular}




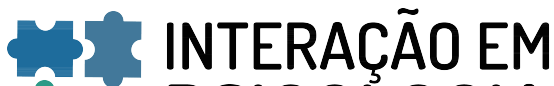 ET PSICOLOGIA}

justificativas para a elaboração de instrumentos psicológicos, além do uso em avaliações, é o de verificar a pertinência dos modelos teóricos. Isso se dá especialmente em estudos de análise fatorial exploratória e confirmatória. O presente trabalho não fez uso de tais análises, o que ocorreu em outras pesquisas (Freitas, 2016; Freitas, Schelini \& Pérez, 2017). No entanto, cabe mencionar tais técnicas porque, por meio delas, aspectos teóricos são refutados ou melhor definidos.

\section{CONSIDERAÇÕES FINAIS}

Escalas de nomeação por professores são consideradas um dos métodos mais utilizados na identificação de alunos com D\&T em outros países (Siegle, et al., 2010; Worrel \& Erwin, 2011). O presente trabalho dá um passo nesse sentido, pois é o primeiro instrumento criado no país para auxiliar no processo de identificação de indivíduos com D\&T, até onde se pode verificar. Jarosewich, Pfeiffer e Morris (2002) à época, já ressaltavam que 0 momento era propício para desenvolvimento de novos instrumentos para a área de D\&T, de modo que os pesquisadores deste campo pudessem refletir sobre as formas de se pensar a questão da D\&T e do desenvolvimento dessas características. Além disso, a identificação de D\&T tende a contribuir com o desenvolvimento psicológico e educacional de indivíduos subnomeados.

No entanto, este trabalho é limitado, visto que novas pesquisas devem ser realizadas com a EIDT, ampliando as amostras e deixando-as mais heterogêneas e representativas da população. Não foi calculado, ainda, o índice de concordância entre juízes para cada domínio, somente para toda a escala. Todavia, deve-se levar a cabo outros estudos que evidenciem a precisão do instrumento e que busquem explorar sua estrutura fatorial e outras evidências de validade, para além dos resultados apresentados por Freitas et al. (2017). Estas são metas a serem alcançadas futuramente por meio da aplicação da EIDT em uma amostra representativa da população, viabilizando a utilização de técnicas de análise fatorial e correlacionais, de forma a propiciar a investigação das evidências de validade fatorial e de critério do instrumento. Assim, pesquisas futuras deverão responder a uma pergunta crucial: Em que medida houve correspondência entre a definição operacional e a conceitual ou entre o fenômeno D\&T?

A oferta de novas medidas psicológicas tende a ajudar substancialmente psicólogos, educadores e demais profissionais atuantes na área de D\&T, visto que as intervenções educacionais se beneficiam bastante de trabalhos que fomentam construtos práticos importantes.
Márcia de Fátima Rabello Lovisi de Freitas e Patrícia Waltz Schelini

\section{CONTRIBUIÇÃO DE CADA AUTOR}

M.F.R.L.F. planejamento e elaboração do manuscrito, decorrente do seu projeto de doutorado. P.W.S. orientação e supervisão.

\section{DECLARAÇÃO DE CONFLITOS DE INTERESSES}

Os autores declaram que não há conflitos de interesses no presente artigo.

\section{REFERÊNCIAS}

Barbosa, A. J. G., Schelini, P. W., \& Almeida, L. C. (2012). Medidas de dotação e talento: Produção científica em psicologia (2006-2011). Em E. Boruchovitch, A. A. A. Santos \& E. Nascimento (Orgs.), Avaliação psicológica nos contextos educativo e psicossocial (pp. 33-52). São Paulo: Casa do Psicólogo.

Campos, C. R., \& Nakano, T. C. (2012). Produção científica sobre avaliação da inteligência: o estado da arte. Interação Psicol.,16 (2), 271-282. http://dx.doi.org/ 10.5380/psi.v16i2.22619

Conselho Federal de Psicologia, [CFP], (2003). Resolução 002/2003, define e regulamenta o uso, a elaboração e a comercialização de testes psicológicos e revoga a Resolução CFP n ${ }^{\circ}$ 025/2001. Retirado de http:// site.cfp.org.br/wp-content/uploads/2003/03/ resolucao2003_02_Anexo.pdf

França-Freitas, M. L. P, Del Prette, A., \& Del Prette, Z. A. P. (2014). Social skills of gifted and talented children. Estudos de Psicologia, 19 (4), 288-295. http://dx.doi.org/ 10.1590/S1413-294X2014000400006

Freitas, M. F. R. L. (2016). Escala de identificação de dotação e talento: Construção de instrumento e validade de conteúdo. Tese de doutorado. Centro de Ciências Humanas e Letras, Universidade Federal de São Carlos, São Paulo.

Freitas, M. F. R. L., Schelini, P. W.; \& Pérez, E. R. (2017). Escala de identificação de dotação e talento: Estrutura e consistência internas. Psico-USF, 22 (3), 473-484. http:// dx.doi.org/10.1590/1413-82712017220308

Gagné, F. (1994). Are teachers really poor talent detectors? Comments on Pegnato and Birch's (1959) study of the effectiveness and efficiency of various identification techniques. Gifted Child Quarterly, 38 (3), 124-126. http:// dx.doi.org/10.1177/001698629403800305

Gagné, F. (2013). The DMGT: Changes within, beneath, and beyond. Talent Development \& Excellence, 5 (1), 5-19.

Gardner, H., Chen, J., \& Moran, S. (2010). Inteligências múltiplas ao redor do mundo. Porto Alegre: Artmed. 


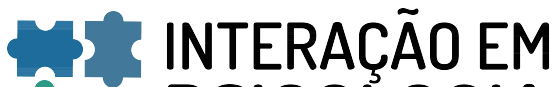 ET PSICOLOGIA}

Hedlund, J., \& Sternberg, R. J. (2002). Inteligências em excesso? Integrando as inteligências social, emocional e prática (R. C. Costa, Trad.). Em R. Bar-On \& J. D. A. Parker (Eds.). Manual de inteligência emocional (pp. 111-131). Porto Alegre: Artmed.

Heller, K. A. (2004). Identification of gifted and talented students. Psychology Science, 46 (3), 302-323.

Heller, K. A. (2005). Education and counseling of the gifted and talented in Germany. International Journal for the Advancement of Counseling, 27 (2), 191-210. http:// dx.doi.org/10.1007/s10447-005-3181-7

Heller, K. A. (2012). Different research paradigms concerning giftedness and gifted education: shall ever they meet? High Ability Studies, 23 (1), 73-75. http://dx.doi.org/ 10.1080/13598139.2012.679097

Heller, K. A., \& Perleth, C. (2008). The Munich High Ability Test Battery (MHBT): a multidimensional, multimethod approach. Psychology Science Quarterly, 50 (2), 173-188.

Heller, K. A.; Perleth, C., \& Lim, T. K. (2005). The Munich model of giftedness designed to identify and promote gifted students. In R. J. Sternberg \& J. E. Davidson (Eds.), Conceptions of giftedness (2nd ed., pp. 147-170). New York: Cambridge University Press.

Hodge, K. A., \& Kemp, C. R. (2006). Recognition of giftedness in the early years of school: Perspectives of teachers, parents, and children. Journal for the Education of the Gifted, 30 (2), 164-204.

Horowitz, F. D. (2009). Introduction: a developmental understanding of giftedness and talent. In F. D. Horowitz, R. F. Subotnik, D. J. Matthews (Eds.), The development of giftedness and talent across the life span (pp. 3-19). Washington: American Psychological Association.

International Test Commission (2013). ITC guidelines on test use.

Jarosewich, T., Pfeiffer, S. I., \& Morris, J. (2002). Identifying gifted students using teacher rating scales: A review of existing instruments. Journal of Psychoeducational Assessment, 20 (4), 322-336. http://dx.doi.org/ $10.1177 / 073428290202000401$

Kaufman, S. B., \& Sternberg, R. J. (2008). Conceptions of giftedness. In S. I. Pfeiffer (Ed.), Handbook of giftedness in children: psychoeducational theory, research, and best practices (pp. 71-91). New York: Springer.

Kim, K. H. (2011). The creativity crisis: The decrease in creative thinking scores on the Torrance Tests of Creative Thinking. Creativity Research Journal, 23 (4), 285-295. http://dx.doi.org/10.1080/10400419.2011.627805

McGrew, K. S. (2009). CHC theory and the human cognitive abilities project: Standing on the shoulders of the giants of psychometric intelligence research. Intelligence, 37 (1), 110. http://dx.doi.org/10.1016/j.intell.2008.08.004
Márcia de Fátima Rabello Lovisi de Freitas e Patrícia Waltz Schelini

Nakano, T. C., \& Siqueira, L. G. C. (2012). Validade de conteúdo da Gifted Rating Scale (versão escolar) para a população brasileira. Avaliação Psicológica, 11 (1), 123-140.

Nisbett, R. E., Aronson, J., Blair, C., Dickens, W., Flynn, J., Halpern, D. F., \& Turkheimer, E. (2012). Intelligence: New findings and theoretical developments. American Psychologist, 67 (2), 130-159. http://dx.doi.org/10.1037/ a0026699

Pasquali, L. (1999). Testes referentes ao construto: Teoria e modelo de construção. Em L. Pasquali (Org.), Instrumentos psicológicos: manual prático de elaboração (pp. 37-71). Brasília: LabPAM.

Primi, R., Muniz, M., \& Nunes, C. H. S. S. (2009). Definições contemporâneas de validade de testes psicológicos. Em C. S. Hutz (Org.), Avanços e polêmicas em avaliação psicológica (pp. 243-265). São Paulo: Casa do Psicólogo.

Renzulli, J. S. (2011). Theories, actions, and change: An academic journey in search of finding and developing high potential in young people. Gifted Child Quarterly, 55 (4), 305-308. doi: 10.1177/0016986211421875

Renzulli, J. S., \& Gaesser, A. H. (2015). Un sistema multicriterial para la identificación del alumnado de alto rendimiento y de alta capacidad creativo-productiva. Revista de Educación, 368, 96-131.

Siegle, D., Moore, M., Mann, R. L., \& Wilson, H. E. (2010). Factors that influence in-service and preservice teachers' nominations of students for gifted and talented programs. Journal for the Education of the Gifted, 33 (3), 337-360.

Sternberg, R. J. (2015). Successful intelligence: A model for testing intelligence beyond IQ tests. European Journal of Educational Psychology, 8, 76-84.

Topping, K., Bremner, W., \& Holmes, E. A. (2002). Competência social: A construção social do conceito (R. C. Costa, Trad.). Em R. Bar-On \& J. D. A. Parker (Eds.). Manual de inteligência emocional (pp. 39-46). Porto Alegre: Artmed.

Worrell, F. C., \& Erwin, J. O. (2011). Best practices in identifying students for gifted and talented education programs. Journal of Applied School Psychology, 27 (4), 319-340. http://dx.doi.org/10.1080/15377903.2011.615817

Recebido em: 04/06/2016 Primeira decisão editorial em: 26/10/2017 Aceito em: 10/01/2018 